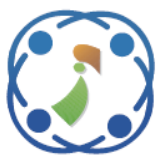

\title{
Speed Control of a Doubly-Fed Induction Motor (DFIM) Based on Fuzzy Sliding Mode Controller
}

\author{
Loukal Keltoum $^{1 *} \quad$ Benalia Leila $^{1} \quad$ Bouguerra Abderrahmen $^{1}$ \\ ${ }^{I}$ Electrical Engineering Research Laboratory, Department of Electrical Engineering, Mohamed Boudiaf \\ University of M'Sila, Algeria \\ * Corresponding author's Email: muohtlek@yahoo.fr
}

\begin{abstract}
The mean of this paper is fuzzy sliding mode control of a Doubly Fed Induction Motor (DFIM); it's the coupling of the fuzzy logic control and sliding mode control (SMC). The use of the sliding mode method provides very acceptable performance for DFIM control, and the chattering phenomenon effect is also eliminated by the fuzzy logic mode. In the first part, we carried out briefly a study of modeling on the full system. This model is intended to facilitate the procedures for setting and controlling the speed. We introduced the parameter variation to test the robustness of the control laws. The results of our simulations are conducted to validate the theory and indicate that the control performance of the DFIM is satisfactory and the proposed fuzzy sliding mode control (FSMC) can achieve favorable tracking performance.
\end{abstract}

Keywords: Doubly Fed Induction Motor (DFIM), Vector Control, Fuzzy Logic, Sliding mode, Fuzzy Sliding mode control.

\section{Introduction}

Since the early years of industrialization, the researchers were faced with "how to control the electric machines at variable speed." Electric drives require high performance, increased reliability, and reduced cost. Among these machines is doubly fed induction machine (DFIM) [1-3] is an asynchronous machine with wound rotor which can be supplied at the same time by the stator and the rotor with external source voltages [4].

It was first studied to be used as a high-speed motor. The many benefits of this machine are: reduced manufacturing cost, relatively simple construction, higher speed and do not require ongoing maintenance. In recent decades, the advances in technology of power electronics and microcomputer, different applications of DFIM became possible. Their interest lies mainly in the speed control options with and without mechanical sensors as well as the regimes in either motor or generator operations with flux control powers for hypo and hyper-synchronous features [5]. For operation at different speeds a converter PWM (Pulse Width Modulation) must be inserted between the machine and the network. Whatever the speed of the machine, the voltage is rectified and an inverter connected to the network side is responsible to ensure consistency between the network frequency and that delivered by the device. The DFIM is essentially nonlinear, due to the coupling between the flux and the electromagnetic torque. The vector control or field orientation control allows a decoupling between the torque and the flux [6] [7].

With the field orientation control (FOC) method, induction machine drives are becoming a major candidate in high-performance motion control applications, where servo quality operation is required. Fast transient response is made possible by decoupled torque and flux control

Sliding mode control (SMC) technique, due to its order diminution, disturbance elimination, robustness and simple realization, is one of the prospective control methodologies for electrical machines [8] [9]. 
The main feature of SMC is the robustness against parameter variations and external disturbances. Various applications of SMC have been conducted, such as robotic manipulators, aircrafts, motors, chaotic systems, and so on [10-12].

SMC has been employed to the control of the many type of machines. But because of the discrete laws control switch feature of SMC, the chattering can occur in the control system [13], [14-16].

Fuzzy logic is a potent tool for controlling illdefined or parameter-variant plants. By generalizing Fuzzy rules, a Fuzzy logic controller can cope well with severe uncertainties. Fuzzy schemes with explicit expressions for tuning can avoid the heavy computational burden [17-20].

In order to reduce or eliminate the phenomena chattering, researches have proposed the fuzzy sliding mode [9] [21] [22], and the adaptive fuzzy sliding mode control for Brushless Doubly Fed Machine [23] and in the power system [24].

In this work, for their simplicity and efficiency to capture the severe nonlinearities of the DFIM, the fuzzy sliding mode control will be used. Till now, fuzzy sliding mode control has been used in very few control applications such as, nonlinear control and the speed control of machines. Nevertheless it is still possible to achieve robustness and highly efficient dynamics using a control technique. This is the case with the controller presented herein where a fuzzy sliding mode controller is designed to achieve the speed stabilization of DFIM. The present work deals with a fuzzy sliding mode controller method for controlling the speed of DFIM in a vectorcontrol mode.

The paper is organized as follows: In Section 2 mathematical model of the DFIM is presented. In section 3, we begin with the DFIM oriented model in view of the vector control; next the stator flux $\phi_{S}$ are estimated. Fuzzy sliding mode is presented in section 4 and gives the design procedure of the proposed controller with the simulation results given in section 5. Finally, some conclusions are drawn in section 6 .

\section{Description and modeling of DFIM}

In the training of high power as the rolling mill, there is a new and original solution using a double feed induction motor (DFIM). The stator is feed by a fixed network while the rotor by a variable supply which can be either a voltage or current source.

The three phase induction motor with wound rotor is doubly fed when, as well as the stator windings being supplied with three phase power at an angular frequency $\omega_{\mathrm{s}}$ the rotor windings are also fed with three phase power at a frequency $\omega$.

The electrical model of the DFIM presented in figure 1 , is expressed in a $(d-q)$ synchronous rotating frame.

\subsection{Reference fixed relative to the rotating field (d, q)}

For a reference related to the rotating field, the following electrical equations are deduced:

$\left[\begin{array}{l}V_{s d} \\ V_{s q}\end{array}\right]=\left[\begin{array}{cc}R_{s} & 0 \\ 0 & R_{s}\end{array}\right]\left[\begin{array}{l}I_{s d} \\ I_{s q}\end{array}\right]+\frac{d}{d t}\left[\begin{array}{c}\Phi_{s d} \\ \Phi_{s q}\end{array}\right]+\left[\begin{array}{cc}0 & -\omega_{s} \\ \omega_{s} & 0\end{array}\right]\left[\begin{array}{l}\Phi_{s d} \\ \Phi_{s q}\end{array}\right]$

$\left[\begin{array}{c}V_{r d} \\ V_{r q}\end{array}\right]=\left[\begin{array}{cc}R_{r} & 0 \\ 0 & R_{r}\end{array}\right]\left[\begin{array}{c}I_{r d} \\ I_{r q}\end{array}\right]+\frac{d}{d t}\left[\begin{array}{c}\Phi_{r d} \\ \Phi_{r q}\end{array}\right]+\left[\begin{array}{cc}0 & -\omega \\ \omega & 0\end{array}\right]\left[\begin{array}{c}\Phi_{r d} \\ \Phi_{r q}\end{array}\right]$

With $I_{s}, I_{r}, V_{s}$ and $V_{r}$ denote stator currents, rotor currents, stator terminal voltage and rotor terminal voltage, respectively.

The subscripts $s$ and $r$ stand for stator and rotor while subscripts $d$ and $q$ stand for vector component with respect to a fixed stator reference frame [25].

The fluxes are given by:

$$
\left\{\begin{array}{l}
\phi_{s d}=l_{s} I_{s d}+M I_{r d} \\
\phi_{s q}=l_{s} I_{s q}+M I_{r q} \\
\phi_{r d}=l_{r} I_{r d}+M I_{s d} \\
\phi_{r q}=l_{r} I_{r q}+M I_{s q}
\end{array}\right.
$$

Where $\phi_{s}, \phi_{r}, I_{s}, I_{r}$ and $M$ represents the stator flux, the rotor flux, the stator inductance, the rotor inductance and the mutual inductance, respectively.

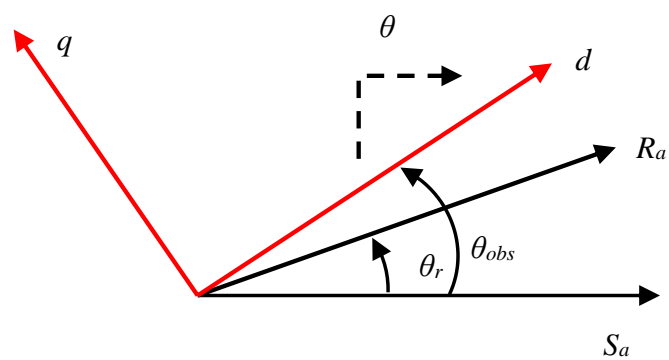

Figure.1 Defining the real axes of DFIM from the reference $(d, q)$ 
Replaces (3) in (1) and (2) we obtained:

$\left\{\begin{array}{l}V_{s d}=R_{s} I_{s d}+l_{s} \frac{d I_{s d}}{d t}+M \frac{d I_{r d}}{d t}-\omega_{s} l_{s} I_{s q}-\omega_{s} M I_{r q} \\ V_{s q}=R_{s} I_{s q}+l_{s} \frac{d I_{s q}}{d t}+M \frac{d I_{r q}}{d t}+\omega_{s} l_{s} I_{s d}+\omega_{s} M I_{r d} \\ V_{r d}=R_{r} I_{r d}+l_{r} \frac{d I_{r d}}{d t}+M \frac{d I_{s d}}{d t}-\omega l_{r} I_{r q}-\omega M I_{s q} \\ V_{r q}=R_{r} I_{r q}+l_{r} \frac{d I_{r q}}{d t}+M \frac{d I_{s q}}{d t}+\omega l_{r} I_{r d}+\omega M I_{s d}\end{array}\right.$

Where $\omega_{s}, \omega, R_{s}$ and $R_{r}$ denote stator pulsation, rotor pulsation, stator resistance and rotor resistance, respectively.

\subsection{DFIM model in the form of state equation}

For the DFIM the control variables are the stator and rotor voltages, [26] by considering:

- An input-output current decoupling is set for all currents;

- The $(d-q)$ frame is oriented with the stator flux;

- Due to the large gap between the mechanical and electrical time constants, the speed can be considered as invariant with respect to the state vector.

Under these conditions, the electrical equations of the machine are described by a time variant state space system as shown in (5)

$$
\begin{gathered}
\dot{X}=A . X+B . U \\
Y=C . X
\end{gathered}
$$

With $X, A, B, U, Y$ and $C$ represent the state vector, system state evolution matrix, matrix of control, vector of the control system, output vector and output matrix (observation matrix) respectively,

Where

$$
\begin{aligned}
& X=\left[\begin{array}{llll}
i_{s d} & i_{s q} & i_{r d} & i_{r q}
\end{array}\right]^{T} \\
& U=\left[\begin{array}{llll}
V_{s d} & V_{s q} & V_{r d} & V_{r q}
\end{array}\right]^{T}
\end{aligned}
$$

Using the frequently adopted assumptions, like sinusoid ally distributed air-gap flux density distribution and linear magnetic conditions and considering the stator voltages $\left(V_{s d}, V_{s q}\right)$ and rotor voltages $\left(V_{r d}, V_{r q}\right)$ as control inputs, the stator current $\left(I_{s d}, I_{s q}\right)$, and the rotor current $\left(I_{r d}, I_{r q}\right)$ as state variables.
From a matrix representation:

$$
\begin{aligned}
& \frac{d}{d t}\left[\begin{array}{c}
I_{s d} \\
I_{s q} \\
I_{r d} \\
I_{r q}
\end{array}\right]=\left[\begin{array}{cccc}
L_{s} & 0 & M & 0 \\
0 & L_{s} & 0 & M \\
M & 0 & L_{r} & 0 \\
0 & M & 0 & L_{r}
\end{array}\right]^{-1} \\
& {\left[\begin{array}{cccc}
a 11 & a 12 & a 13 & a 14 \\
a 21 & a 22 & a 23 & a 24 \\
a 31 & a 32 & a 33 & a 34 \\
a 41 & a 42 & a 43 & a 44
\end{array}\right]\left[\begin{array}{c}
I_{s d} \\
I_{s q} \\
I_{r d} \\
I_{r q}
\end{array}\right]} \\
& +\left[\begin{array}{cccc}
L_{s} & 0 & M & 0 \\
0 & L_{s} & 0 & M \\
M & 0 & L_{r} & 0 \\
0 & M & 0 & L_{r}
\end{array}\right]^{-1}\left[\begin{array}{l}
V_{s d} \\
V_{s q} \\
V_{r d} \\
V_{r q}
\end{array}\right]
\end{aligned}
$$

Let:

$[L]=\left[\begin{array}{cccc}L_{s} & 0 & M & 0 \\ 0 & L_{s} & 0 & M \\ M & 0 & L_{s} & 0 \\ 0 & M & 0 & L_{s}\end{array}\right]$

$[Z]=\left[\begin{array}{llll}a 11 & a 12 & a 13 & a 14 \\ a 21 & a 22 & a 23 & a 24 \\ a 31 & a 32 & a 33 & a 34 \\ a 41 & a 42 & a 43 & a 44\end{array}\right]$

And

$\left\{\begin{array}{l}a 11=a 22=a 33=a 44=-R_{s} \\ a 12=\omega_{s} L_{s} ; a 13=0 ; a 14=\omega_{s} M \\ a 21=-\omega_{s} L_{s} ; a 23=-\omega_{s} M ; \quad a 24=0 \\ a 31=0 ; a 32=\left(\omega_{s}-\omega\right) M ; a 34=0 \\ a 41=-\left(\omega_{s}-\omega\right) M ; a 42=0 ; a 43=-\left(\omega_{s}-\omega\right) L_{r}\end{array}\right.$

Then the equation (5) becomes:

$$
\frac{d X}{d t}=[L]^{-1} \cdot[Z] \cdot X+[L]^{-1} \cdot U
$$

In analogy to equation (9) with equation (5) we find $A=[L]^{-1}$. [Z] and $B=[L]^{-1}$. [25] 


$$
A=\left[\begin{array}{cccc}
-a_{1} & a \omega+\omega_{s} & a_{3} & a_{5} \omega \\
-a \omega-\omega_{s} & -a_{1} & -a_{5} \omega & a_{3} \\
a_{4} & -a_{6} \omega & -a_{2} & -\frac{\omega}{\sigma}+\omega_{s} \\
a_{6} \omega & a_{4} & \frac{\omega}{\sigma}-\omega_{s} & -a_{2}
\end{array}\right]
$$

$$
\begin{gathered}
B=\left[\begin{array}{cccc}
b_{1} & 0 & -b_{3} & 0 \\
0 & b_{1} & 0 & -b_{3} \\
-b_{3} & 0 & b_{2} & 0 \\
0 & -b_{3} & 0 & b_{2}
\end{array}\right] \\
C=\left[\begin{array}{llll}
1 & 0 & 0 & 0 \\
0 & 1 & 0 & 0 \\
0 & 0 & 1 & 0 \\
0 & 0 & 0 & 1
\end{array}\right]
\end{gathered}
$$

Where

$a=\frac{1-\sigma}{\sigma} \quad a_{1}=\frac{R_{s}}{\sigma L_{s}} \quad a_{2}=\frac{R_{r}}{\sigma L_{r}} \quad a_{3}=\frac{R_{r} M}{\sigma L_{S} L_{r}}$ $a_{4}=\frac{R_{s} M}{\sigma L_{s} L_{r}} \quad a_{5}=\frac{M}{\sigma L_{s}} \quad a_{6}=\frac{M}{\sigma L_{r}} \quad b_{1}=\frac{1}{\sigma L_{s}} \quad b_{2}=\frac{1}{\sigma L_{r}}$ $b_{3}=\frac{M}{\sigma L_{s} L_{r}} \quad \sigma=1-\frac{M^{2}}{L_{s} L_{r}}$

$L_{s}, L_{r}$ are stator and rotor cyclic inductances, $\sigma$ is redefined leakage factor. [26]

The generated torque of DFIM can be expressed in terms of stator currents and stator flux linkage as:

$$
C_{e}=\frac{P M}{L_{S}}\left(\phi_{s q} \cdot i_{r d}-\phi_{s d} \cdot i_{r q}\right)
$$

$P$ is number of pole pairs; In addition the mechanical dynamic equation is given by

$$
J \frac{d \Omega}{d t}=C_{e}-C_{r}-f \Omega
$$

$J, C_{e}, C_{r}$, and $f$ denote the moment inertia of the motor, the electromagnetic torque, the external load torque and viscous friction coefficient, respectively. $\Omega$ is the mechanical speed.

\section{Vector control by direct stator flux orientation}

To simplify the control we need to make a judicious choice reference. For this, we place ourselves in a reference $(d, q)$ related to the rotating field with an orientation of the flux stator, according to the condition of the stator flux orientation. [27] [28]

$$
\phi_{s d}=\phi_{s} \& \phi_{s q}=0
$$

By replacing (15) in (1) and (2) we obtain

$$
\left\{\begin{array} { l } 
{ V _ { s d } = R _ { s } I _ { s d } } \\
{ V _ { s q } = R _ { s } I _ { s q } + \omega _ { s } \phi _ { s d } } \\
{ V _ { r d } = R _ { r } I _ { r d } - \omega \phi _ { r q } } \\
{ V _ { r q } = R _ { r } I _ { r q } + \omega \phi _ { r d } }
\end{array} \Leftrightarrow \left\{\begin{array}{l}
\phi_{s q}=0 \Rightarrow I_{s q}=-\frac{M}{L_{s}} I_{r q} \\
I_{s d}=0 \\
I_{r d}=\frac{\phi_{s}^{*}}{M}
\end{array}\right.\right.
$$

The torque equation becomes

$$
\begin{gathered}
C_{e}=-\frac{P M}{L_{S}} \phi_{s}^{*} \cdot I_{r q} \\
I_{r q}=-\frac{L_{S}}{P \cdot M \cdot \phi_{S}^{*}} \cdot C_{e}^{*}
\end{gathered}
$$

Equation (4) was:

$$
\begin{aligned}
\frac{d \theta_{s}}{d t}= & \omega_{s} \\
= & \frac{\frac{R_{s} M}{L_{s}} I_{r q}+V_{s q}}{\phi_{s}^{*}}
\end{aligned}
$$
then:

According to the equation (3) of the stator flux,

$$
\left\{\begin{array}{l}
I_{s d}=\frac{1}{L_{s}}\left(\phi_{s d}-M I_{r d}\right) \\
I_{s q}=\frac{1}{L_{s}}\left(\phi_{s q}-M I_{r q}\right)
\end{array}\right.
$$

From the relations (20) and (4) 


$$
\left\{\begin{array}{l}
\dot{\phi}_{s d}=V_{s d}+\frac{M}{T_{s}} I_{r d}-\frac{1}{T_{s}} \phi_{s d} \\
\dot{\phi}_{s q}=V_{s q}+\frac{M}{T_{s}} I_{r q}-\omega_{s} \phi_{s q}
\end{array}\right.
$$

The relationship of the rotor current

$$
\left\{\begin{array}{c}
\dot{I}_{r d}=-\frac{1}{\sigma}\left(\frac{1}{T_{r}}+\frac{M^{2}}{L_{s} T_{s} L_{r}}\right) I_{r d}-\frac{M}{\sigma L_{s} L_{r}} V_{s d} \\
+\frac{M}{\sigma L_{r} L_{s} T_{s}} \phi_{s d}+\left(\omega_{s}-\omega\right) I_{r q}+\frac{1}{\sigma L_{r}} V_{r d} \\
\dot{I}_{r q}=-\frac{1}{\sigma}\left(\frac{1}{T_{r}}+\frac{M^{2}}{L_{s} T_{s} L_{r}}\right) I_{r q}-\frac{M}{\sigma L_{s} L_{r}} V_{s q} \\
+\frac{M}{\sigma L_{r} L_{s}} \omega \phi_{s d}-\left(\omega_{s}-\omega\right) I_{r d}+\frac{1}{\sigma L_{r}} V_{r q}
\end{array}\right.
$$

The relationship of the mechanical speed

$$
\frac{d \Omega}{d t}=\frac{P \cdot M}{J \cdot L_{s}}\left(I_{r q} . \phi_{s d}\right)-\frac{C_{r}}{J}-\frac{f}{J} \Omega
$$

Where $T_{s}=L_{s} / R_{s}$ and $T_{r}=L_{r} / R_{r}$ are stator and rotor time-constant respectively. [20]

\subsection{Stator flux estimator}

In the direct vector control stator flux oriented DFIM, precise knowledge of the amplitude and the position of the stator flux vector is necessary.

In motor mode of DFIM, the stator and rotor currents are measured whereas the stator flux can be estimated [26]. The flux estimation may be obtained by the following equations

$$
\left\{\begin{array}{l}
\phi_{s d}=l_{s} I_{s d}+M I_{r d} \\
\phi_{s q}=l_{s} I_{s q}+M I_{r q}
\end{array}\right.
$$

The position stator flux is calculated by the following equations:

$$
\theta_{r}=\theta_{s}-\theta
$$

In which:

$$
\theta_{s}=\int \omega_{s} d t \quad, \theta=\int \omega d t
$$

$\omega=P \Omega$ and $\theta_{s}$ is the electrical stator position, $\theta$ is the electrical rotor position.

\section{Fuzzy sliding mode control of DFIM}

Sliding mode control is a variable structure control (VSC). Basically, VSC includes several different continuous functions which map the plant state to the control surface.

The switching among these functions is determined by the plant state which is represented by the switching function. [29]

\subsection{Speed control method}

To apply the sliding mode control theory to the speed of DFIM, follow the steps in the design of a sliding control. The speed control is done by control the rotor current $I_{r d}$. So the control law:

$$
I_{r q}^{r e f}=I_{r q}^{e q}+I_{r q}^{s}
$$

The speed error is defined by:

$$
e=\Omega_{r e f}-\Omega
$$

The expression of the speed control surface:

$$
S(\Omega)=\Omega_{r e f}-\Omega
$$

With

$$
\dot{S}(\Omega)=\dot{\Omega}_{r e f}-\dot{\Omega}
$$

Substituting the expression of $\Omega$ equation (23) in equation (30), we obtain:

$$
\dot{S}(\Omega)=\dot{\Omega}_{r e f}-\left(-\frac{P . M}{J \cdot L_{s}}\left(I_{r q} . \phi_{s d}\right)-\frac{C_{r}}{J}-\frac{f}{J} \Omega\right)
$$

By replacing the current $I_{r d}$ we obtain:

$$
\begin{aligned}
\dot{S}(\Omega)= & \dot{\Omega}_{r e f}-\left(-\frac{P . M . \phi_{s d}^{r e f}}{J . L_{s}} I_{r q}^{e q}\right. \\
& \left.+\frac{P . M \cdot \phi_{s d}^{r e f}}{J \cdot L_{s}} I_{r q}^{s}-\frac{C_{r}}{J}-\frac{f}{J} \Omega\right)
\end{aligned}
$$

Lyapunov function $V$ defined by

$$
V=\frac{1}{2} S(\Omega)^{2}
$$




$$
\dot{V}=S(\Omega) \dot{S}(\Omega)
$$

During the convergence of lyapunov function, the condition $\tilde{V}(\Omega)=S(\Omega) . \dot{S}(\Omega)<00$ must be checked.

In the sliding mode and in permanent regime, we have $S(\Omega)=0, \dot{S}(\Omega)=0, I_{r q}^{s}=0$.

Where the equivalent control is:

$$
I_{r q}^{e q}=-\frac{J . L_{s}}{P . M . \phi_{s d}^{r e f}}\left(\dot{\Omega}_{r e f}+\frac{C_{r}}{J}+\frac{f}{J} \Omega\right)
$$

Therefore, the correction factor is given by:

$$
I_{r q}^{s}=-K_{I_{r q}} . \operatorname{Sign}(S(\Omega))
$$

To verify the system stability condition, the constant $K_{I r q}$ must be positive.

\subsection{Fuzzy sliding mode controller design}

The conventional sliding mode controller produces high frequency oscillations in its outputs, causing a problem known as chattering. The chattering is undesirable because it can excite the high frequency dynamics of the system. To eliminate chattering, a continuous fuzzy logic control $u_{f}$ is used to approximate the discontinuous control $K_{\text {Irq }} \operatorname{sign}(S(\Omega)$ ), (Fig. 2). We chose the triangular and trapezoidal membership functions because of the simplicity of implementation, when the number of the functions increases the stability increases. The membership functions for input and output variables are chosen in Fig. 3.

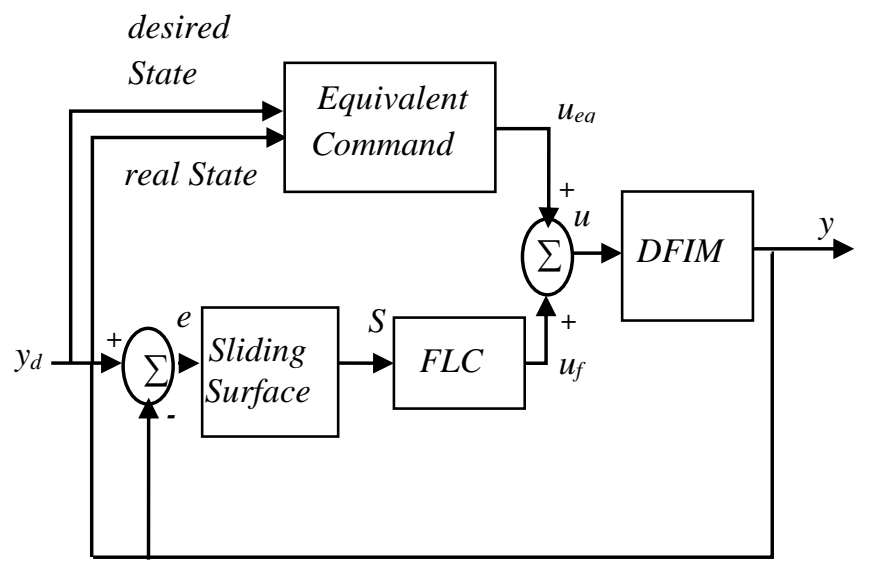

Figure.2 Fuzzy Sliding Mode control of the speed

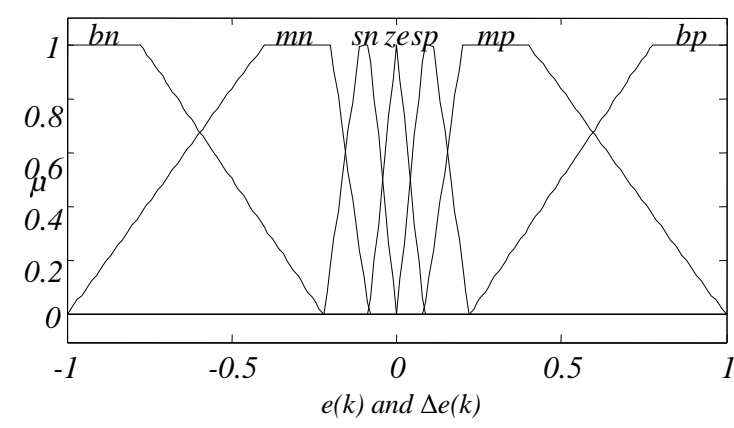

(a)

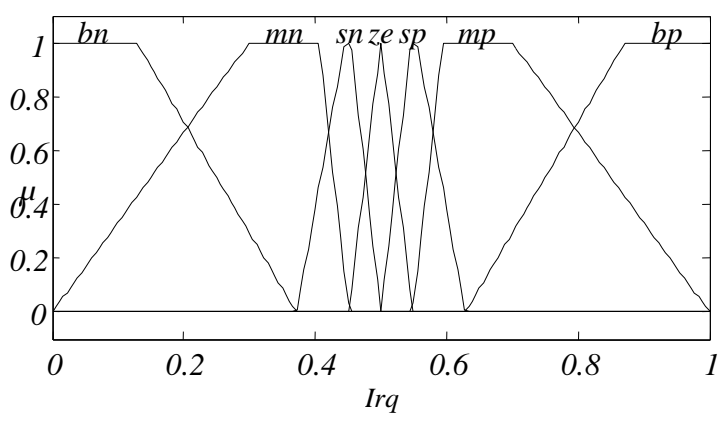

(b)

Figure.3 Membership functions for the inputs and the output [30]: (a) inputs and (b) output

Table 1. Fuzzy tuning rules for outputs

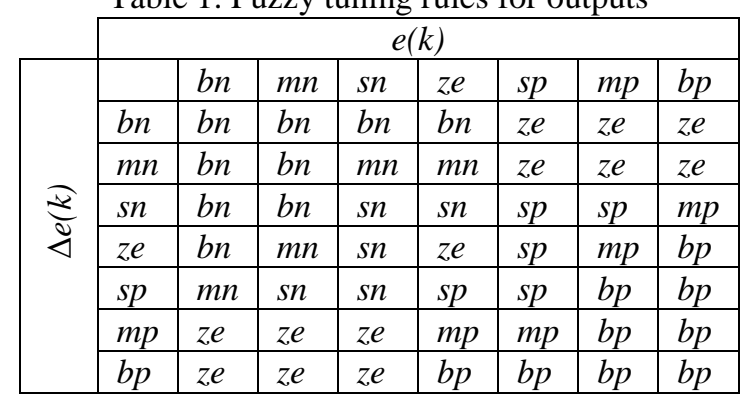

Table 1 show the linguist rules used in the Fuzzy Logic Controller. In these table, $n, p, z e, s, m, b$ represent negative, positive, approximately zero, small, medium, and big respectively. For example $b n$ means big negative, and so on.

The linguistic rules of FSM controller are:

$$
\text { if } S_{i} \text { is } A_{i} \text { and } \Delta S_{i} \text { is } B_{i} \text { then } u_{f i} \text { is } C_{i}
$$

Where $A_{i}, B_{i}$ and $C_{i}$ are the fuzzy sets corresponding to $S_{i}, \Delta S_{i}$ and $u_{f i}$ respectively. 
Table 2. DFIM parameters [25]

\begin{tabular}{|l|l|l|}
\hline Definition & Symbol & Value \\
\hline $\begin{array}{l}\text { DFIM Mechanical } \\
\text { Power }\end{array}$ & $P_{w}$ & $4 \mathrm{~kW}$ \\
\hline Stator voltage & $U_{s n}$ & $380 \mathrm{~V}$ \\
\hline rotor voltage & $U_{r n}$ & $220 \mathrm{~V}$ \\
\hline Nominal current & $I_{n}$ & $3.8 / 2.2 \mathrm{~A}$ \\
\hline $\begin{array}{l}\text { Nominal mechanical } \\
\text { speed }\end{array}$ & $\Omega_{n}$ & $1420 \mathrm{rpm}$ \\
\hline $\begin{array}{l}\text { Nominal stator and } \\
\text { rotor frequencies }\end{array}$ & $\omega_{s n}$ & $50 \mathrm{~Hz}$ \\
\hline Pole pairs number & $\mathrm{P}$ & 2 \\
\hline Stator resistance & $R_{s}$ & $11.98 \Omega$ \\
\hline rotor resistance & $R_{r}$ & $0.904 \Omega$ \\
\hline Stator self inductance & $L_{s}$ & $0.414 \mathrm{H}$ \\
\hline rotor self inductance & $L_{r}$ & $0.0556 \mathrm{H}$ \\
\hline mutual inductance & $\mathrm{M}$ & $0.126 \mathrm{H}$ \\
\hline Moment of inertia & $J$ & $0.01 \mathrm{Kg} . \mathrm{m} 2$ \\
\hline friction coefficient & $f$ & $0.00 \mathrm{IS}$ \\
\hline
\end{tabular}

\section{Results and discussion}

In this section, simulations results are presented to illustrate the performance and robustness of proposed control law when applied to the DFIM. The parameters values of the motor as shown in Table. 2.

The motor is operated at $157 \mathrm{rad} / \mathrm{s}$ under no load and a load disturbance torque $(5 \mathrm{~N} . \mathrm{m})$ is suddenly applied at $t=0.6 \mathrm{~s}$ and eliminated at $t=1.6 \mathrm{~s}(-5 \mathrm{~N} . \mathrm{m})$, and the rotor resistance variations (increase at $100 \%$ of nominal value rotor resistance), while the other parameters are held constant.

\subsection{Comparison between SMC and FSMC}

The responses of speed, torque, stator flux and rotor current are shown in Figures 4-11.

The fuzzy logic control is used to mimic the hitting control law to remove the chattering. Compared with the conventional sliding mode controller, the fuzzy sliding mode control system results in robust control performance without chattering. The chattering free improved performance of the FSMC makes it superior to conventional SMC, and establishes its suitability for the system drive.

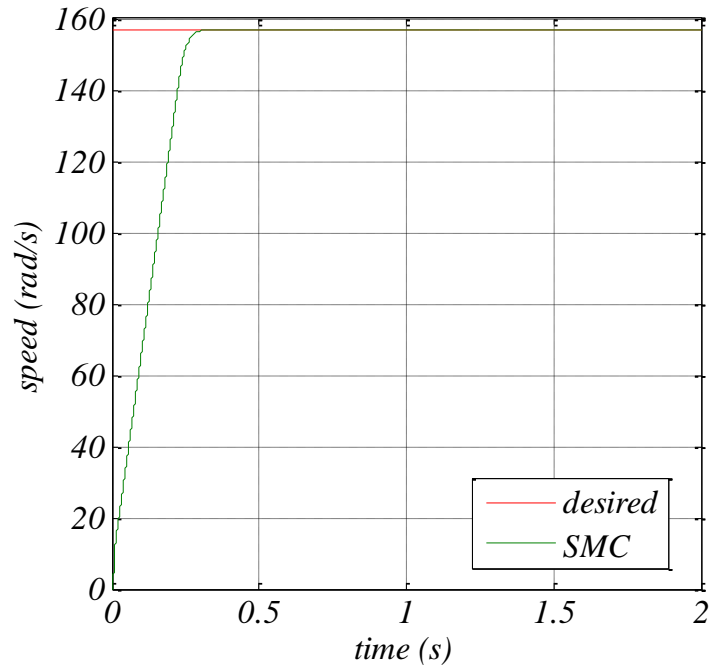

Figure.4 Result of the speed with Sliding mode controller

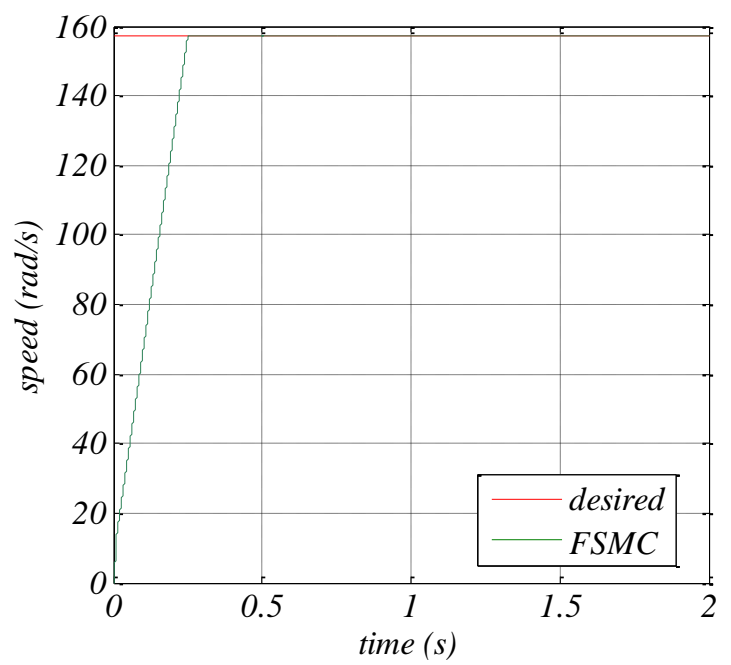

Figure.5 Result of the speed with Fuzzy Sliding mode controller

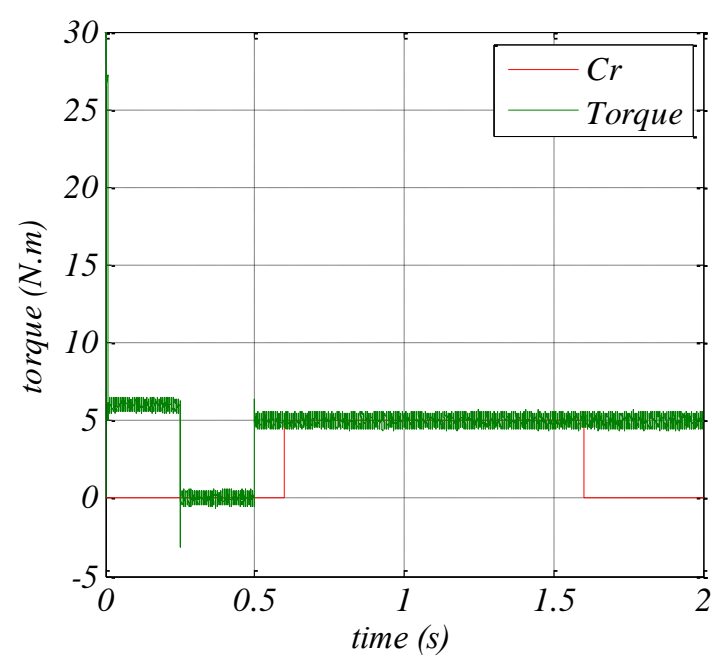

Figure.6 Result of the torque with Sliding mode controller 


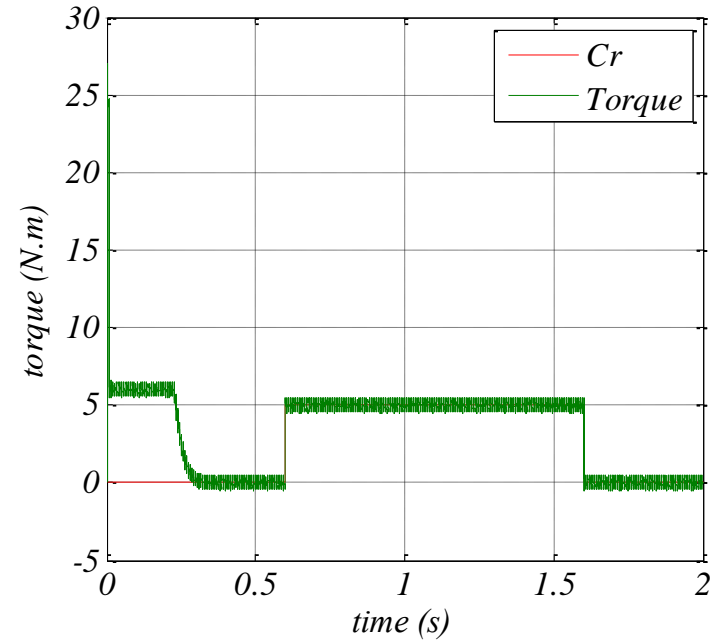

Figure.7 Result of the torque with Fuzzy Sliding mode controller

The results of the speed control have shown that the control with fuzzy sliding mode controller ensures good dynamic performance with respect to the control with sliding mode controller even in the presence of parametric variations and external disturbances.

We remark in the Fig. 7 a net amelioration of the results of the fuzzy sliding mode method compared with the sliding mode method. In fact, the elimination of the chattering problem permits the smoothness of the control law.

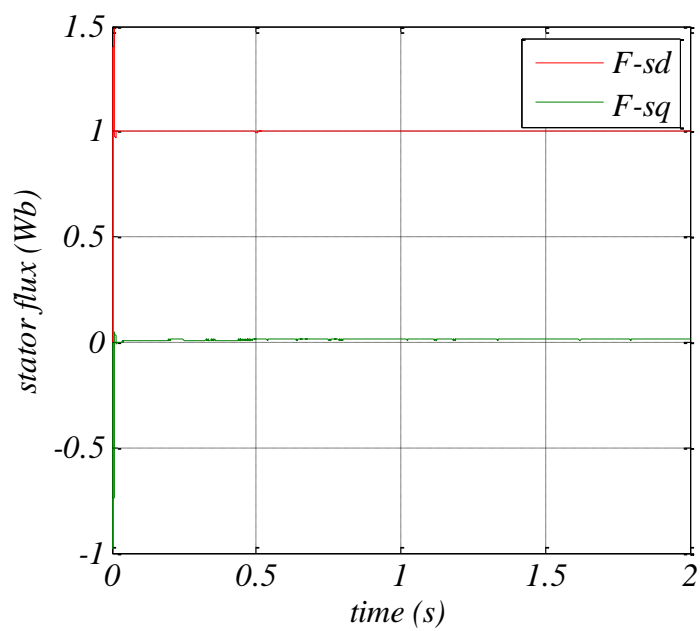

Figure. 8 Result of the rotor current with Sliding mode controller

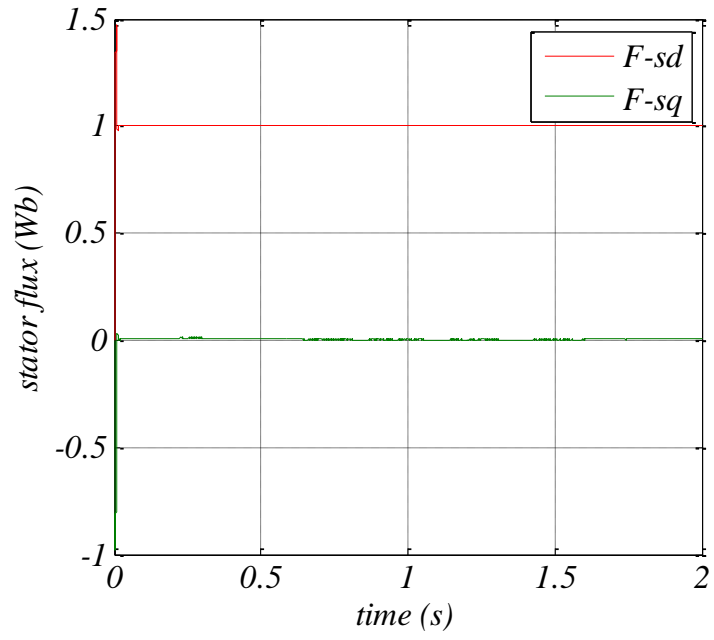

Figure.9 Result of the rotor current with Fuzzy Sliding mode controller

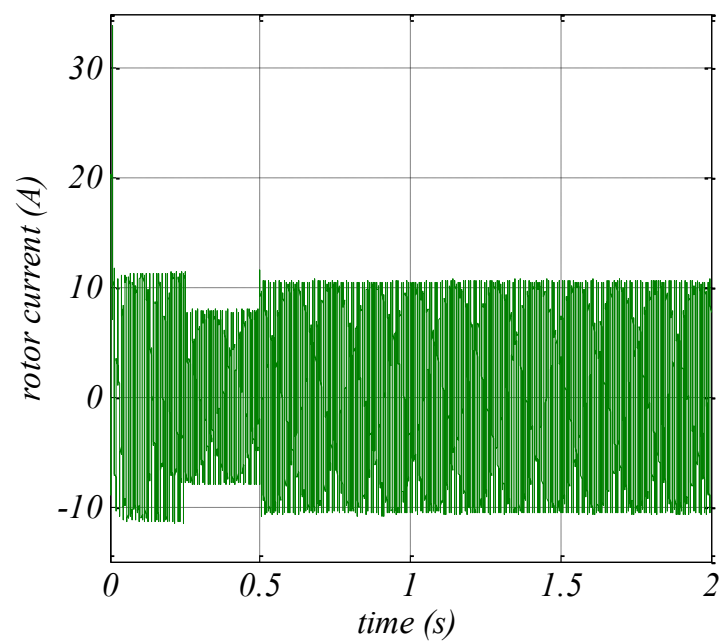

Figure.10 Result of the stator flux with Sliding mode controller

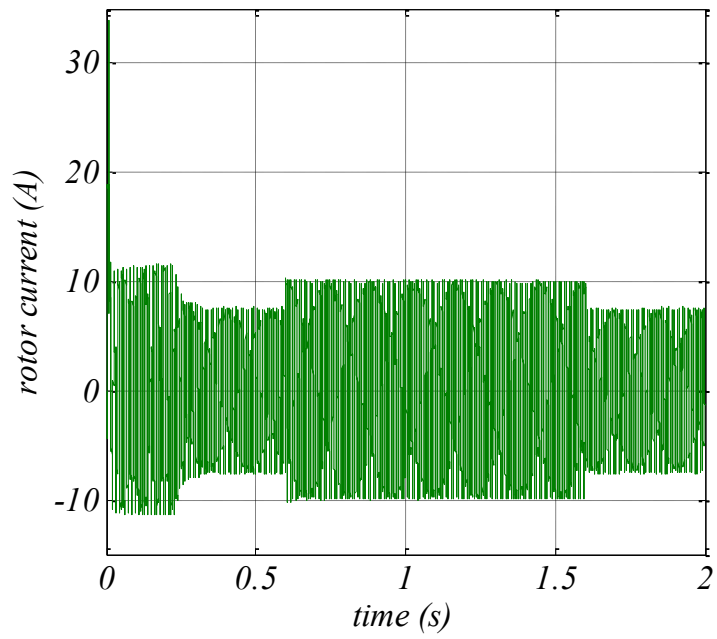

Figure.11 Result of the stator flux with Fuzzy Sliding mode controller 


\section{Conclusion and future works}

In this paper, the speed regulation of DFIM with two controllers, sliding mode (SMC) and fuzzy sliding (FSMC) controller has been designed and simulated. The comparative study shows that the FSMC controller can be improve the performances of speed of the DFIM control. The simulation results have confirmed the efficiency of the FSMC controller for different working conditions. The results show that the FSMC controller has good performance, and it is robust against exterior perturbations.

In the futures works we propose another controls techniques for example the type 2 fuzzy sliding mode controller, fusion of neural networks with fuzzy techniques, high-order sliding mode control and the adaptive interval type 2 fuzzy controller of the DFIM.

\section{References}

[1] P. E. Vidal, Commande non-linéaire d'une machine asynchrone à double Alimentation, Doct. Thesis, Dept. of Elect. Eng., National Polytechnic Institute of Toulouse, France, 2004.

[2] G. Salloum, Contribution à la commande robuste de la machine asynchrone à double alimentation, Doct. Thesis, Dept. of Elect. Eng, National Polytechnic Institute of Toulouse, France, 2007.

[3] M. S. Vicatos and J. A. Tegopoulos, "A Doubly-fed induction machine differential drive model for automobiles", IEEE Trans. Ene. Conv., Vol. 18, No. 2, pp.225-230, 2003.

[4] Y. Bekakra, D. Ben attous, "Speed and flux control for DFOC of doubly fed induction machine using sliding mode controller", Acta Electrotechnica et Informatica, Vol. 10, No. 4, pp.75-81, 2010.

[5] J. C. Prescott, B.P. Raju, "The inherent instability of induction motors under condition of double supply", In: Proc. of the IEE, The Institute of Electrical Engineers Monograph, Vol. 105, No. 7, pp.319-330, 1958.

[6] E. Blaschke, "The principe of field orientation as applied to the new transvector closed loop control system for rotating field machine", Siemens Review, Vol. 34, pp.217-220, 1972.

[7] M. Chaari, M. Soltani, M. Gossa, "Comparative study between the conventional regulators and fuzzy logic controller: application on the induction machine," International Journal of Sciences and Techniques of Automatic control \& computer engineering IJ-STA, Vol. 1, No. 2, pp.196-212, 2007.
[8] A. Boucheta, I. K. Bousserhane, A. Hazzab, B. Mazari, M. K. Fellah, "Fuzzy-Sliding Mode Controller for Linear Induction Motor Control", Rev. Roum. Sci. Techn. - Électrotechn. et Énerg., Vol. 54, No. 4, pp.405-414, 2009.

[9] A. Bouguerra, S. Zeghlache, K. Loukal, D. Saigaa, "Fault Tolerant Fuzzy Sliding Mode Controller of Brushless DC Motor (BLDC MOTOR)", the Mediterranean Journal of Measurement and Control, Vol. 12, No. 2, pp.585-597, 2016.

[10] Y. J. Huang and T. C. Kuo, "Robust position control of DC servomechanism with output measurement noise", Electr. Eng., Vol. 88, No. 3, pp.223-238, 2006.

[11] P. Guan, X. J. Liu, and J. Z. Liu, "Adaptive fuzzy sliding mode control for flexible satellite", Engineering Appl. Arti Intelli., Vol. 18, No. 4, pp.451-459, 2005.

[12] H. S. Choi, Y. H. Park, Y. S. Cho, and M. Lee, "Global sliding-mode control improved design for a brushless DC motor", IEEE Control Systems Magazine, Vol. 21, No. 3, pp.27-35, 2001.

[13] M. Zhiwen, T. Zheng, F. Lin, X. You, “A New Sliding-Mode Current Controller for Field Oriented Controlled Induction Motor Drives", IEEE Int. Conf. IAS, pp.1341-1346, 2005.

[14] J. J. Slotine, Applied nonlinear control, Printice Hall, 1996.

[15] V. I. Utkin, "Sliding Mode Control Design Principles and Applications to Electric Drives", IEEE Trans. Ind. Electr., Vol. 40, No. 1, pp.2336, 1993.

[16] R. J. Wai, "Adaptive Sliding-Mode Control for Induction Servomotor Drives", IEE Proc. Elecr. Power Appl., Vol. 147, No. 6 pp.553-562, 2000.

[17] A. J. Koshkouei and A. S. I. Zinober, "Sliding mode controller-observer design for SISO linear systems", Int. J. systems Science, Vol. 2, pp.1363-1373, 1998.

[18] S. V. Drakunov and V. I. Utkin, "Sliding mode control in dynamic systems", Int. J. Control, Vol. 55, No. 4, pp.1029-1037, 1992.

[19] T. C. Manjunath, "Design of Moving Sliding Surfaces in A Variable Structure Plant \& Chattering Phenomena", International Journal of Mechanical, Aerospace, Industrial, Mechatronic and Manufacturing Engineering, Vol. 1, No. 9, pp.536-542, 2007.

[20] M. G. Sarwer, M. A. Rafiq and B. C. Ghosh, "Sliding Mode Speed Controller of a D.C Motor Drive", Journal of Electrical Engineering, The Institution of Engineers, Bangladesh ,Vol. 31, No. 1 \& 2, 2004. 
[21] K. M. Arun Prasad, A. Unnikrishnan, N. Usha, "Fuzzy Sliding Mode Control of a Switched Reluctance Motor", Procedia Technology, Vol. 25, pp.735-742, 2016.

[22] Y. Yuntao and L. Yan, "A Novel Sensorless Fuzzy Sliding-Mode Control of Induction Motor", International Journal of Control and Automation, Vol. 8, No. 9, pp.1-10, 2015.

[23] Z. Shao, Y. Zhan, “Adaptive Fuzzy Sliding Mode Control for Brushless Doubly Fed Machine", Second International Symposium on Computational Intelligence and Design, Vol. 2, pp.73-77, 2009.

[24] F. Rashidi , M. Rashidi, H. Amiri, "An adaptive fuzzy sliding mode control for power system stabilizer", Industrial Electronics Society, the $29^{\text {th }}$ Annual Conference of the IEEE, Vol. 1, pp.626-630, 2003.

[25] L. Benalia, Control of a double feed and double star induction machine using direct torque control, Prof. Moulay Tahar Lamchich (Ed.), InTech, pp.113-126, 2011.

[26] D. Ben Attous and Y. Bekakra, "Speed control of a doubly fed induction motor using fuzzy logic techniques", International Journal on Electrical Engineering and Informatics, Vol. 2, No. 3, pp179-191, 2010.

[27] M. Machmoum, F. Poitiers, L. Moreau, M. E. Zaim and E. Le- doeuff, Etude d'éolienne à vitesse variable basées sur des machines asynchrones (MAS-MADA), Polytechnic Institute of Nantes, France, 2003.

[28] A. Farrokh payam, M. Jalalifar, "Robust speed sensorless control of doubly-fed induction machine based on input-output feedback linearization control using a sliding-mode observe", International conference on power electronics, drives and energy systems, Vol. 10, No. 11, pp.1392-1400, 2010.

[29] F. Xiang, Block-oriented nonlinear control of pneumatic actuator systems, Doctoral thesis, Department of Machine Design, Royal Institute of Technology, Sweden, 2001.

[30] H. A. Mohammad, C. Abbas, Z. Youmin, "Fault-Tolerant Fuzzy Gain-Scheduled PID for a Quadrotor Helicopter Testbed in the Presence of Actuator Faults", IFAC Conference on Advances in PID Control PID'12, pp.28-30, 2012. 